\title{
Cholelithiasis in Children with Sickle Cell Disease in Ouagadougou Pediatric Hospital
}

\author{
Fla Kouéta ${ }^{1,2 *}$, Sonia Kaboret ${ }^{1,2}$, Caroline Yonaba ${ }^{1,3}$, Aïssata Kaboré1,2, Lassina Dao ${ }^{1,2}$, \\ Sak-Wend-Tongo Daïla², Hamidou Savadogo², Emile Bandré1,4, Diarra Yé1,2 \\ ${ }^{1}$ Training and Research Unit of Health Sciences, University of Ouagadougou, Ouagadougou, Burkina Faso \\ ${ }^{2}$ Service of Medical Pediatrics, Charles de Gaulle Pediatric University Teaching Hospital, Ouagadougou, Burkina \\ Faso \\ ${ }^{3}$ Department of Pediatrics, Yalgado University Teaching Hospital, Ouagadougou, Burkina Faso \\ ${ }^{4}$ Pediatric Surgery Service, Charles de Gaulle Pediatric University Teaching Hospital, Ouagadougou, Burkina \\ Faso \\ Email: ${ }^{*}$ kouetafla@yahoo.com
}

Received 4 August 2015; accepted 6 September 2015; published 9 September 2015

Copyright (C) 2015 by authors and Scientific Research Publishing Inc.

This work is licensed under the Creative Commons Attribution International License (CC BY). http://creativecommons.org/licenses/by/4.0/

(c) (i) Open Access

\section{Abstract}

Introduction: Sickle cell disease (SCD) causes chronic hemolysis which is a risk factor for cholelithiasis. Its development may lead to severe and life-threatening complications. Objective: Determine the prevalence of cholelithiasis, the conditions of diagnosis and related factors. Materials and Method: We retrospectively reviewed records of 110 patients with sickle cell disease followed up in Charles de Gaulle University Pediatric Hospital from January 2003 to December 2013, including 103 patients who had abdominal ultrasonography. Results: Cholelithiasis prevalence was $24.3 \%$. The mean age of patients was 10.8 years, (range 3 to 15 years). Sex ratio was 2.1 . In $88 \%$ cases, cholelithiasis was diagnosed based on the characteristic symptoms of right hypocondrial pain, fever and icterus. Most factors associated with cholelithiasis were as follows: age above 10 years $(O R=4)$, occurrence of at least three $(03)$ vaso-occlusive crises per year $(O R=7.6)$, history of blood transfusion $(O R=8)$, right hypochondrial pain $(O R=4.5)$ and icterus $(O R=15)$. Only $20 \%$ of patients suffering from a symptomatic cholelithiasis underwent laparoscopic cholecystectomy and results were conclusive. Conclusion: Patients with sickle cell disease, especially those aged above 10, should be routinely tested for cholelithiasis using abdominal ultrasonography at least once a year. Because of the difficulties in managing evolutive complications in case of an emergency in our context, we advocate laparoscopic cholecystectomy of any cholelithiasisas soon as it is diagnosed in children with sickle cell disease.

\footnotetext{
${ }^{*}$ Corresponding author.
} 


\section{Keywords}

\section{Cholelithiasis, Sickle Cell Disease, Children}

\section{Introduction}

Cholelithiasis is a frequent complication of chronic hemolysis due to sickle cell disease (SCD) [1]. It is sometimes revealed by digestive symptoms difficult to distinguish from painful abdominal vaso-occlusive crises (recurrent abdominal pain sometimes similar to biliary colic, nausea, vomiting). However, cholelithiasis is often asymptomatic and can lead to serious complications (cholecystitis, cholangitis, pancreatitis, septicemia starting in the bile) which can jeopardize patients' lives [2] [3]. If excessive bilirubin excretion related to chronic hemolysis is a major risk factor for gallstones formation, other conducive factors which have not been identified yet could intervene [1] [4]. Many studies show that the prevalence of cholelithiasis in patients with sickle cell disease increases with age and affects $6 \%$ of patients before 15 years of age and more than $50 \%$ of young adults [1] [5] [6]. Gallstones treatment is equivocal but most of studies recommend cholecystectomy in the symptomatic cases and regular ultrasonography in the other cases [3] [7]. In Charles de Gaulle University Pediatric Hospital of Ouagadougou, children with SCD have been followed up since 2002 but patients have to bear the fees [8]. Ultrasonography is not always accessible due to its cost. The diagnosis of cholelithiasis is often based on clinical signs and the risk of developing complications is high. It is in this context that we found it appropriate to carry out this study to determine the prevalence of cholelithiasis, the conditions of diagnosis, the factors associated with its occurrence and the treatment adapted to our context of limited resources.

\section{Patients and Methods}

We carried out a retrospective study to describe and review the records of all patients with SCD followed up in Charles de Gaulle University Pediatric Hospital (CHUP-CDG) between January $1^{\text {st }}$, 2003 and December $31^{\text {st }}$, 2013. During the period of study, 110 patients with SCD were followed up every 3 months and had at least one biological checkup every 6 months based on full blood count far away from any complication. Annual abdominal ultrasonography was routinely proposed to all patients. It was also performed in case of abdominal pain or in the occurrence of clinical signs of symptomatic cholelithiasis. Thus, one hundred and three (103) patients had had abdominal ultrasonography during the period of study, either routinely or with the occurrence of warning signs and these were all included in the study. For each patient, we collected data on clinical monitoring and/or hospitalization records and on epidemiological aspects (age, sex, parents' socioeconomic status), clinical data (pathological history, motives for consultation, physical examination data), paraclinical data (hemoglobin electrophoresis, full blood count, abdominal ultrasonography, biochemical checkup: serum transaminase, bilirubinemia), data on medical and surgical treatment and on the course of the disease. Parents' socioeconomic status was arbitrarily classified according to the father's occupation and divided into two (02) categories: average socioeconomic level (civil servants, liberal professions, traders, the military and paramilitary); low socioeconomic level (farmers, breeders, informal sector, the unemployed, pupils, students).

To identify epidemiological, clinical and biological factors likely to be associated with the occurrence of cholelithiasis, we compared patients suffering from cholelithiasis (Group I) with the other patients whose abdominal ultrasonography was normal (Group II). Data were collected and analyzed on microcomputer with Epi-Info software, Version 3.5.1. Group I (cases) and group II (witnesses) were compared using the Chi-squared test at a significance level of $5 \%$ and calculation of Odds ratio with their confidence intervals (IC) at 95\%. Factors in which the confidence interval did not include the value 1 were deemed to be high risk factors for cholelithiasis occurrence.

\section{Results}

\subsection{Epidemiological Data}

\subsubsection{Prevalence of Cholelithiasis}

Out of 103 patients with SCD who had had an abdominal ultrasonography, 25 suffered from cholelithiasis, 
hence a prevalence of 24.3\%. Hemoglobin electrophoresis revealed 14 SC patients (56\%) and 11 SS patients (44\%) among patients suffering from cholelithiasis.

\subsubsection{Distribution of Cholelithiasis Cases by Age and Sex}

Patients' mean age during cholelithiasis diagnosis was 10.8 years (range- 3 to 15 years). The age group from 10 to 15 years was the most affected with 16 cases (64\%) (see Table 1). We registered 17 boys (68\%) and 8 girls (32\%). Sex-ratio was 2.1.

\subsubsection{Socioeconomic Level}

The socioeconomic level was deemed average in 17 parents (68\%) and low in 8 parents (32\%).

\subsection{Clinical Data}

\subsubsection{Frequency of Vaso-Occlusive Crises}

Out of 25 patients, 23 had a history of vaso-occlusive crises including 20 who experienced more than 3 vaso-occlusive crises per year, representing $80 \%$ of cases.

\subsubsection{History of Transfusion}

Ten (10) patients had already had at least one blood transfusion, representing $40 \%$.

\subsubsection{Conditions of Diagnosis}

Right hypocondrial pain (68\%), fever (60\%) and icterus (56\%) were the main conditions for diagnosing cholelithiasis, as shown in Table 2 . Only 3 cases of cholelithiasis were routinely detected.

\subsubsection{Physical Signs}

On examination, some general signs were observed: a mucocutaneous paleness in 12 patients (48\%) and icterus in the other14 patients (56\%). Physically, 14 patients (56\%) felt a pain at deep palpation of right hypocondrium and 03 patients $(12 \%)$ presented with persistent pain in the same hypocondrium. Hepatomegaly and splenomegaly were observed in 6 (24\%) and 2 cases (8\%), respectively. For 8 patients (32\%), physical examination was normal.

\subsection{Paraclinical Data}

\subsubsection{Results of Abdominal Ultrasonography}

Abdominal ultrasonography objectived a gall bladder containing gallstones in 24 cases and "Sludge" in 01 case. In 05 cases, gallstones size ranged from 10 to $27 \mathrm{~mm}$ in diameter with a mean size of $14.60 \mathrm{~mm}$. In 19 patients, we observed "multi-microlithiases" with gallstones measuring less than $5 \mathrm{~mm}$ in diameter and in 1 case, a "small lithiasis" measuring between 5 and $10 \mathrm{~mm}$. Moreover, all patients had normal sonographic patterns of liver and common bile duct. Ultrasonography revealed complications such an acute cholecystitis in 07 patients, representing $28 \%$ of cases.

\subsubsection{Results of Biological Examinations}

Full blood count revealed hemoglobin level below $6 \mathrm{~g} / \mathrm{dl}$ in 6 patients (24\%) and ranging from 06 to $10 \mathrm{~g} / \mathrm{dl}$ in the other 19 patients (76\%). A hyperleucocytosis above 15,000 white blood cells $/ \mathrm{mm}^{3}$ was observed in 16 cases

Table 1. Distribution of the 25 cholelithiasis patients by age and sex.

\begin{tabular}{|c|c|c|c|}
\hline \multirow{2}{*}{ Range of age (years) } & \multicolumn{2}{|c|}{ Sex } & \multirow{2}{*}{ Total n $(\%$} \\
\hline & Female n (\%) & Male n (\%) & \\
\hline$<5$ & $1(4)$ & $3(12)$ & $4(16)$ \\
\hline $6-10$ & $1(4)$ & $4(16)$ & $5(20)$ \\
\hline $11-15$ & $6(24)$ & $10(40)$ & $16(64)$ \\
\hline Total & $8(32)$ & $17(68)$ & $25(100)$ \\
\hline
\end{tabular}


Table 2. Conditions of diagnosis of the 25 cases of cholelithiasis.

\begin{tabular}{ccc}
\hline Conditionof diagnosis & Number & (\%) \\
\hline Right hypocondrial pain & 17 & 68 \\
Fever & 15 & 60 \\
Icterus/subicterus & 14 & 56 \\
Diffuse abdominal pain & 04 & 16 \\
Nausea/vomiting & 03 & 12 \\
Dark urines & 02 & 8 \\
Routine diagnosis & 03 & 12 \\
\hline
\end{tabular}

(64\%) with predominant neutrophils.

Other lab tests revealed high serum transaminase in $46 \%$ of patients and high total bilirubin in $60 \%$ of cases. Moreover, creatinemia and blood sugar turned normal in all our patients.

\subsection{Therapeutic Aspects}

Out of 25 cases of cholelithiasis, 19 were hospitalized and the other 6 were followed up as outpatients. Patients were initially admitted in pediatric care unit, then, 9 patients were transferred to surgical care unit in the same hospital. Medical treatment often consisted in healing clinical and biological disorders observed and it was associated with a symptomatic treatment made up of analgesic, anti-inflammatory and antispasmodic medicines. In surgical care unit, 5 patients underwent a cold laparoscopic cholecystectomy within a mean time of 17.4 days after cholelithiasis was diagnosed through abdominal ultrasonography (range—04 to 34 days).No major surgery aftermath was reported in all cases. The mean hospital stay was 7.4 days (range- 01 to 19 days) with on average 9 days in pediatric care unit and 5 days in pediatric surgery.

After hospital stay, patients were proposed a monthly, 3 months and then half-yearly follow-up as well as abdominal ultrasonography. Most of patients failed to have abdominal ultrasonography. After one year's follow-up, 14 patients who were not operated became asymptomatic under medical treatment and 4 patients were lost to follow up.

\subsection{Factors Associated with Cholelithiasis}

Table 3 shows epidemiological and clinical factors likely to be associated with the occurrence of cholelithiasis in our patients. Age above 10 years $(\mathrm{OR}=4)$, occurrence of at least 3 vaso-occlusive crises per year $(\mathrm{OR}=7.6)$, history of blood transfusion ( $\mathrm{OR}=8)$, right hypocondrial pain $(\mathrm{OR}=4.5)$ and icterus $(\mathrm{OR}=15)$ were mainly associated with cholelithiasis.

\section{Discussion}

Sickle cell disease is a genetic disease that causes anemia as well as acute and chronic tissue injuries in many organs [1]. Providing better care in our unit has increased the life expectancy of children with SCD [8]. Yet, its development can lead to chronic complications such as cholelithiasis which should be known and managed. Despite the retrospective nature of our study, which could introduce bias in the estimation of the prevalence of gallstones and especially symptomatic forms, we have achieved significant results and conducted the following discussion.

\subsection{Prevalence of Cholelithiais}

Prevalence of cholelithiasis in children with SCD varies according to studies. We observed a prevalence of 24.3\% in our series. Our results are similar to those of Athanassiou-Metaxa and al in Greece [9] who reported a frequency of $27.1 \%$. Other authors as Silva in Greece and Itoua in Nigeria [10] [11] reported a prevalence greatly superior to ours, $40.9 \%$ and $31.30 \%$ respectively. However, many other African studies reported lower prevalence: 9.3\% in Côte d'Ivoire, 9.4\% in Senegal and 11.5\% in Sudan [1] [2] [12]. Differences observed 
Table 3. Factors associated with cholelithiasis.

\begin{tabular}{|c|c|c|c|c|}
\hline \multirow{2}{*}{ Factors } & Group I & Group II & OR (IC95\%) & \multirow{2}{*}{$\mathrm{p}$} \\
\hline & $(n=25)$ & \multicolumn{2}{|l|}{$(\mathrm{n}=78)$} & \\
\hline \multicolumn{5}{|c|}{ Type of hemoglobin } \\
\hline SC & 14 & 41 & $1(0.4-3)$ & 0.7 \\
\hline SS & 11 & 37 & 1.0 & \\
\hline \multicolumn{5}{|l|}{ Age } \\
\hline$>10$ years & 16 & 20 & $5(1.8-15.2)$ & 0.0004 \\
\hline$\leq 10$ years & 9 & 58 & 1.0 & \\
\hline \multicolumn{5}{|l|}{ Sex } \\
\hline male & 17 & 45 & $1.6(0.7-4.5)$ & 0.3 \\
\hline female & 8 & 33 & 1.0 & \\
\hline \multicolumn{5}{|c|}{ Socioeconomic level } \\
\hline low & 8 & 36 & $0.6(0.2-1.6)$ & 0.2 \\
\hline average & 17 & 42 & 1.0 & \\
\hline \multicolumn{5}{|c|}{ Vaso-occlusive crises $\geq 3 /$ an } \\
\hline yes & 20 & 27 & $7.6(2.3-26.1)$ & 0.00007 \\
\hline no & 5 & 51 & 1.0 & \\
\hline \multicolumn{5}{|c|}{ History of blood transfusion } \\
\hline Yes & 10 & 06 & $8(2.2$ - 29.9) & 0.001 \\
\hline no & 15 & 72 & 1.0 & \\
\hline \multicolumn{5}{|c|}{ Right hypocondrial pain } \\
\hline Yes & 17 & 30 & $4.5(1.6-13.3)$ & 0.001 \\
\hline no & 8 & 48 & 1.0 & \\
\hline \multicolumn{5}{|l|}{ Icterus } \\
\hline yes & 14 & 06 & $15(4.3-57.4)$ & $<10^{-6}$ \\
\hline no & 11 & 72 & 1.0 & \\
\hline
\end{tabular}

between prevalences could be related to patients' age in the series, their mode of selection or clinical signs. In our study, the relatively high prevalence of cholelithiasis can be explained inter alia by better care provision to patients with SCD and increased access to ultrasonography, which is an essential tool in the diagnosis of this pathology. Diagne and al in Senegal [2] reported that cholethiais on the whole occurred less frequently in patients of West Africa than in those of Central Africa. This would be related to the fact that in case of SCD, the Bantu haplotype which is more frequent in Central Africa experiences more severe symptoms with chronic and more important hemolysis whereas the Senegal and Benin haplotype which is the majority in West Africa presents with less severe symptoms. The intermingling of populations could progressively reduce the scope of this observation.

\subsection{Conditions of Diagnosis}

Conditions under which cholelithiasis is diagnosed in children with SCD vary according to series. In our study as in Sarnaik and al [13] and Bond and al [14], cholelithiasis was, from the onset, diagnosed in case of symptoms evocative of bile ducts disorders (right hypocondrial pain, icterus and fever) in 88\%, 60\% and 56\% of cases, respectively. On the other hand, in the work of Attala [1] and Parez [3], cholelithiasis was initially detected through a routine ultrasonography. The diagnosis of cholelithiasis with clinical signs is a late diagnosis. This 
situation is prejudicial to patients due to high risk of death if complications occur [2]. Recurrent high temperature $(60 \%)$ and cholecystitis in $28 \%$ of cases reveal in our series major complications in children with SCD. Annual abdominal ultrasonography required for the follow-up of our patients should therefore be done routinely and free of charge for parents who are unable to bear fees.

\subsection{Factors Associated with the Occurrence of Cholelithiasis}

Factors that lead to gallstones formation in case of chronic hemolysis such as sickle cell disease have not been fully understood [15]. In our study, age above 10 years, occurrence of at least 3 vaso-occlusives crises per year, history of blood transfusion, right hypocondrial pain and icterus were reported. These observations are similar to those of literature in which the prevalence of cholelithiasis in patients with SCD always increases with age and seriousness of disease [1] [2] [3] [7]. However, if an increased bilirubin excretion related to chronic or recurrent hemolysis remains a significant factor for cholelithiaisis occurrence, all patients who experience an important hemolysis do not develop cholelithiasis. Other contributory factors play therefore a complementary role. According to Everson et al. [4], some defects of biliary function and the metabolism of bile acids may contribute. Moreover, some authors reported the role of food factors (fatty food and diet low in fiber) in patients living in Europe and USA [16] [17]. Factors leading to cholelithiasis are numerous, equivocal and depend on age. It is therefore possible that early care while reducing the exposure to factors aggravating chronic hemolysis, reduces the risk of cholelithiasis.

\subsection{Therapeutic Aspects}

In our series, only $20 \%$ of patients with symptomatic cholelithiasis underwent laparoscopic cholecystectomy. Despite the equivocal treatment attitude towards cholelithiasis, most of studies agree on cholecystectomy in symptomatic forms [1]-[3]. In asymptomatic forms, two attitudes are opposed. Some authors advocate abstention and follow-up [7] [18] whereas other authors recommend cold cholecystectomy before the onset of any complication [19] [20]. In our context, the second attitude seems more reasonable because of fear of complications in case of emergency. But this attitude is faced with financial difficulties and sometimes the reluctance of parents who fear the aftermath of surgery which was simple in all our operated patients.

Laparoscopic cholecystectomy is the treatment of choice of cholelithiasis in children with SCD, because of its effectiveness and harmlessness in comparison with laparotomy which is a classical surgery [21]. This technique is used recently though uncommon in our health center. Considering challenges for obtaining regular ultrasonography during follow-up of patients and difficulties in the management of complications in case of emergency, we recommend as Parez and al in Paris and Diagne and al in Dakar [2] [3], the routine laparoscopic cholecystectomy in any patient with SCD showing or not a symptomatic cholelithiasis.

\section{Conclusion}

Cholelithiasis is frequent in children with SCD in Burkina Faso. It should be routinely screened using ultrasonography in any patient with SCD, especially those above 10 years of age. Because of the difficulties in managing evolutive complications in case of an emergency in our context, we advocate laparoscopic cholecystectomy way of all gallstones since its discovery in sickle cell children. The implementation of a national programme of sickle cell disease, the introduction of a routine neonatal screening and a regular follow-up could contribute to reduce morbidity and mortality in children with SCD in our country.

\section{Conflict of Interest}

No.

\section{References}

[1] Attalla, B.A.I., Karrar, Z.A., Ibnouf, G., Mohamed, A.O., Abdelwahab, O., Nasir, E.M., et al. (2013) Outcome of cholelithiasis in Sudanese children with Sickle Cell Anaemia (SCA) after 13 Years Follow-Up. African Health Sciences, 13, 154-159. http://dx.doi.org/10.4314/ahs.v13i1.21

[2] Diagne, I., Badiane, M., Moreira, C., Signaté-Sy, H., Ndiaye, O., Lopez-Sail, P., et al. (1999) Lithiase biliaire et drépanocytose homozygote en pédiatrie à Dakar (Sénégal). Archives de Pédiatrie, 6, 1286-1292. 
http://dx.doi.org/10.1016/S0929-693X(00)88890-9

[3] Parez, N., Quinet, B., Batut, S., Grimprel, E., Larroquet, M., Audry, G., et al. (2001) Lithiase biliaire chez l'enfant drépanocytaire: Expérience d’un hôpital pédiatrique parisien. Archives de Pédiatrie, 8, 1045-1049. http://dx.doi.org/10.1016/S0929-693X(01)00581-4

[4] Everson, G.T., Nemeth, A., Kourourian, S., Zogy, D., Leff, N.B., Dixon D., et al. (1989) Gallbladder Function Is Altered in Sickle Haemoglobinopathy. Gastroenterology, 96, 1307-1316.

[5] Akinyanju, O. and Ladapo, F. (1979) Cholelithiasis and Biliary Tract Disease in Sickle Cell Disease in Nigerians. Postgraduate Medical Journal, 55, 400-402. http://dx.doi.org/10.1136/pgmj.55.644.400

[6] Dos Santos, G.A.P., Bellomo-Brandão, M.A. and Da Costa-Pinto, E.A.L. (2008) Gallstones in Children with Sickle Cell Disease Followed up at a Brazilian Hematology Center. Arquivos de Gastroenterologia, 45, 313-318. http://dx.doi.org/10.1590/S0004-28032008000400010

[7] Serjeant, B.R. and Serjeant, B.E. (1993) Management of Sickle Cell Disease; Lessons of Jamaïcan Cohort Study. Blood Reviews, 7, 137-145. http://dx.doi.org/10.1016/0268-960X(93)90001-K

[8] Yé, D., Kouéta F., Dao, L., Kaboret, S. and Sawadogo, A. (2008) Prise en charge de la drépanocytose en milieu pédiatrique: Expérience du centre hospitalier universitaire pédiatrique Charles-de-Gaulle de Ouagadougou (Burkina Faso). Santé, 18, 70-75.

[9] Athanassiou-Metaxa, M., Tsatra, I. and Koussi, A. (2002) Lithiase biliaire chez les patients drépanocytaires: L'expérience grecque. Archives de Pédiatrie, 8, 878. http://dx.doi.org/10.1016/S0929-693X(02)00014-3

[10] Silva, I.V., Reis, A.F., Palare, M.J., Ferrao, A., Rodrigues, T. and Morais, A. (2015) Sickle Cell Disease in Children: Chronic Complications and Search of Predictive Factors for Adverse Outcomes. European Journal of Haematology, 94, 157-161. http://dx.doi.org/10.1111/ejh.12411

[11] Itoua-Ngaporo, A., Ngoma, K. and Paris, J.C. (1987) La prevalence de la lithiase biliaire dans la drépanocytose homozygote. Médecine et Chirurgie Digestives, 16, 479-482.

[12] Abby, C.B., Sangaré, A., Bougouma, A., Méité, M., Kéita, A., Djédjé, A.T., et al. (1996) Lithiase biliaire et drépanocytose. Rev Méd Côte-d'Ivoire, 78, 27-31.

[13] Sarnaik, S., Slovis, T.L., Corbett, D.P., Emami, A. and Whitten, C.F. (1980) Incidence of Cholelithiasis in Sickle Cell Anemia Using the Ultrasonic Gray-Scale Technique. The Journal of Pediatrics, 96, 1005-1008. http://dx.doi.org/10.1016/S0022-3476(80)80626-3

[14] Bond, L.R., Hatty, S.R., Horn, M.E.C., Dick, M., Meire, H.B. and Bellingham, A.J.G. (1987) Stones in Sickle Cell Disease in the United Kingdom. BMJ, 295, 234-236. http://dx.doi.org/10.1136/bmj.295.6592.234

[15] Bogue, C.O., Murphy, A.J., Gerstle, J.T., Moineddin, R. and Daneman, A. (2010) Risk Factors, Complications, and Outcomes of Gallstones in Children: A Singlecenter Review. Journal of Pediatric Gastroenterology \& Nutrition, 50, 303-308. http://dx.doi.org/10.1097/MPG.0b013e3181b99c72

[16] Nzeh, D.A. and Adedoyin, M.A. (1989) Sonographic Pattern of Gallbladder Disease in Children with Sickle Cell Anaemia. Pediatric Radiology, 19, 290-292. http://dx.doi.org/10.1007/BF02467294

[17] Werlin, S.L. and Scott, J.P. (1996) Is Biliary Sludge a Stone-in-Waiting? The Journal of Pediatrics, 129, $321-322$. http://dx.doi.org/10.1016/S0022-3476(96)70061-6

[18] Durosinmi, M.A., Ogunseyinde, A.O., Olatunji, P.O. and Esnas, J.F. (1989) Prevalence of Cholelithiasis in Nigerians with Sickle-Cell Disease. African Journal of Medical Sciences, 18, 223-227.

[19] Stephens, C.G. and Scott, R.B. (1980) Cholelithiasis in Sickle Cell Anaemia: Surgical or Medical Management. Archives of Internal Medicine, 140, 648-651. http://dx.doi.org/10.1001/archinte.1980.00330170064026

[20] Malone, B.S. and Werlin, S.L. (1988) Cholecystectomy and Cholelithiasis in Sickle Cell Anaemia. American Journal of Diseases of Children, 142, 799-800.

[21] Diop, N., Diao-Bah, M., Ndiaye-Pape, L., Diouf, E., Kane, O., Bèye, M., et al. (2008) Priseen charge peri-operatoire de la cholecystectomie par voielaparoscopique chez l'enfantdrépanocytaire homozygote. Archives de Pédiatrie, 15, 1393-1397. http://dx.doi.org/10.1016/j.arcped.2008.06.012 